\title{
Effects of Foliar Se Spraying on the Physiological Characteristics of Pakchoi
}

\author{
Mingliang Wang ${ }^{1 a}$, Ziyi Zhao ${ }^{1 b}$, Xinqian Shi ${ }^{1 c}$, Mei Han ${ }^{2 d}$, Huifen Liu ${ }^{1 e}$
}

1. College of Agronomy and Resources \& Environment, Tianjin Agricultural University, Tianjin 300384, P.R.China

2. Agriculture and Water Affairs Service Center, Xiditou Town, Beichen District, Tianjin City,Tianjin 300408, P.R.China

aemail 837035936@qq.com; bemail 770155191@qq.com; 'email 11591150432@qq.com; demail

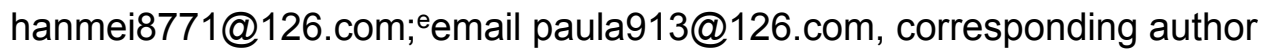

Keywords: Pakchoi; Se fertilizer; Photosynthetic characteristics; Protective enzyme activity Abstract: Selenium (Se) is a kind of important trace elements in organisms, and selenium deficiency or excess will lead to human disease, therefore, it is of great significance to study the application of selenium fertilizer. In this study, through using pot experiment with selenium rich soil collected from Xiqing District of Tianjin, the effects of foliar spraying selenium fertilizer on the physiological characteristics of pakchoi were studied under different fertilization treatments. The results showed that the application of organic fertilizer and compound fertilizer can increase the net photosynthetic rate, transpiration rate and stomatal conductance of pakchoi leaves, and two times spraying Se can increase photosynthetic characteristics of pakchoi, while under the treatment without spraying Se, the intercellular $\mathrm{CO}_{2}$ concentration of pakchoi leaves was higher. Under the application of organic fertilizer, the activity of SOD and CAT was increased by two times spraying Se, while, the POD activity was increased by foliar spraying Se under the application of compound fertilizer

\section{Introduction}

Selenium was an indispensable and important nutrient element for the growth and development of organism. $72 \%$ regions in China was lack of Se or low $\mathrm{Se}^{[1]}$, so Se supplementation has become a serious problem. In the ecological environment, selenium exists mainly in two forms: organic Se and inorganic $\mathrm{Se}^{[2]}$. But the human body can't absorb the inorganic selenium, and it has to be converted into organic selenium through plant body. The human body gets Se through food, vegetables and other crops. Selenium can promote the growth of plants, and also have a great influence on the energy metabolism and chlorophyll synthesis of crops. In addition, Se participates in the activity centers that make up some enzymes, such as the thioxin reductase and dehydrogenase, and has a strong antioxidant effect which can change the activity of SOD, POD and CAT ${ }^{[3]}$. Selenium in moderate concentration can increase the porosity of leaf surface and increase the flux of $\mathrm{CO}_{2}$, thus increasing the photosynthetic rate of plants ${ }^{[4]}$. Low concentration of selenium (below $2.0 \mathrm{mg} / \mathrm{L}$ ) improved the plant growth, while, high concentration of selenium (above $4.0 \mathrm{mg} / \mathrm{L}$ ) inhibited the growth of cabbage and significantly reduced the activity of some enzymes in pakchoi ${ }^{[5]}$. Chinese cabbage has a strong ability of selenium enrichment, and different fertilization has great influence on its physiological characteristics and quality [6]. In this study, the effect of selenium fertilizer on photosynthetic characteristics and protective enzyme activity was investigated through pot experiment in order to provide a reference for the rational application of foliar Se fertilizer in agricultural production. 


\section{Experimental materials and methods}

\section{Experimental materials}

The Se-rich soil $(0-20 \mathrm{~cm})$ was collected from the greenhouse vegetable field in Xiqing district of Tianjin. The pakchoi cultivar is Jinzhi 30. The compound fertilizer (organic matter $\geq 20.0 \%$, the total nutrient $\geq 15.8 \%$, moisture $\leq 12.0 \%$, pH5.8 8.0, N- $\mathrm{P}_{2} \mathrm{O}_{5}-\mathrm{K}_{2} \mathrm{O}$ 4-11-0.8) was provided by Tianzi Environmental Protection Investment Holdings, and the organic fertilizer (main ingredients are rotted chicken manure)and chemical fertilizer (urea) was provided by Tianjin Greenplanting and Animal Nutrition Technology Development Co., Ltd. The conventional fertilizer is cow manure. The contents of nutrient and some heavy metals in the compound fertilizer and organic fertilizer were shown in Table 1.

Table 1 Content of some nutrient elements and heavy metals in compound fertilizer and organic fertilizer

\begin{tabular}{lcccccccc}
\hline Fertilizer & $\mathrm{N}$ & $\begin{array}{c}\mathrm{P}_{2} \mathrm{O}_{5} \\
(\%)\end{array}$ & $\mathrm{K}_{2} \mathrm{O}$ & $\mathrm{As}$ & $\mathrm{Cd}$ & $\begin{array}{l}\mathrm{Cr}^{6+} \\
(\mathrm{mg} / \mathrm{kg})\end{array}$ & $\mathrm{Hg}$ & $\mathrm{Pb}$ \\
\hline compound fertilizer & 3.3 & 6.2 & 1.5 & 1.5 & 0.0 & 0.0 & 0.7 & 12.0 \\
organic fertilizer & 1.1 & 2.5 & 1.1 & 0.7 & 0.0 & 0.0 & 0.4 & 7.3 \\
\hline
\end{tabular}

\section{Experiment design}

12 treatments were designed in the experiment, including conventional fertilization (T1), conventional fertilization + foliar spraying Se (T2), organic manure (T3), organic manure + foliar spraying Se (T4), compound fertilizer (T5), compound fertilizer + foliar spraying Se (T6), chemical fertilizer (T7), chemical fertilizer + foliar spraying Se(T8), conventional fertilization + two times foliar spraying Se (T9), organic manure + two times foliar spraying Se (T10), compound fertilizer + two times foliar spraying Se (T11), chemical fertilizer + two times foliar spraying Se (T12). Completely random design with 3 replicates was used. Each pot was filled with $5 \mathrm{~kg}$ soil, and the application rates of compound fertilizer, organic fertilizer and chemical fertilizer were $66.96 \mathrm{~g}, 133.9$ $\mathrm{g}$ and $1.34 \mathrm{~g}$ per pot respectively. The conventional fertilization was applied with rotted cow manure after the winter harvest. 20 seeds of pakchoi were sowed in each pot. After 10 days, 10 seedlings were remained and watered every $2 \sim 3 \mathrm{~d}$ during their growth period, to keep the soil moisture being about $70 \%$ of the water content in the field. The foliar Se fertilizer (named Xizhiyuan, bought from Anhui Yulong New Materials Technology Co. Ltd) was sprayed for the first time after 28 days of pakchoi growing and was sprayed for the second time after 35 days growing.

\section{Experimental indicator and determination method}

The content of chlorophyll (SPAD value) was determined by using portable chlorophyll detector (SPAD-502). The photosynthetic rate and transpiration rate of pakchoi leaf was determined by photosynthesizer(LI-6400XT). The activity of POD, SOD and CAT was determined by using guaiacol method, NBT photochemical reduction and ultraviolet spectrophotometry, respectively.

\section{Data processing and analysis}

The single factor variance analysis was performed with SPSS17.0 software, and Duncan method was used in multiple comparisons $(\mathrm{p}<0.05)$. 


\section{Results and analysis}

The effects of foliar spraying Se on the photosynthetic characteristics of pakchoi under different fertilization treatments
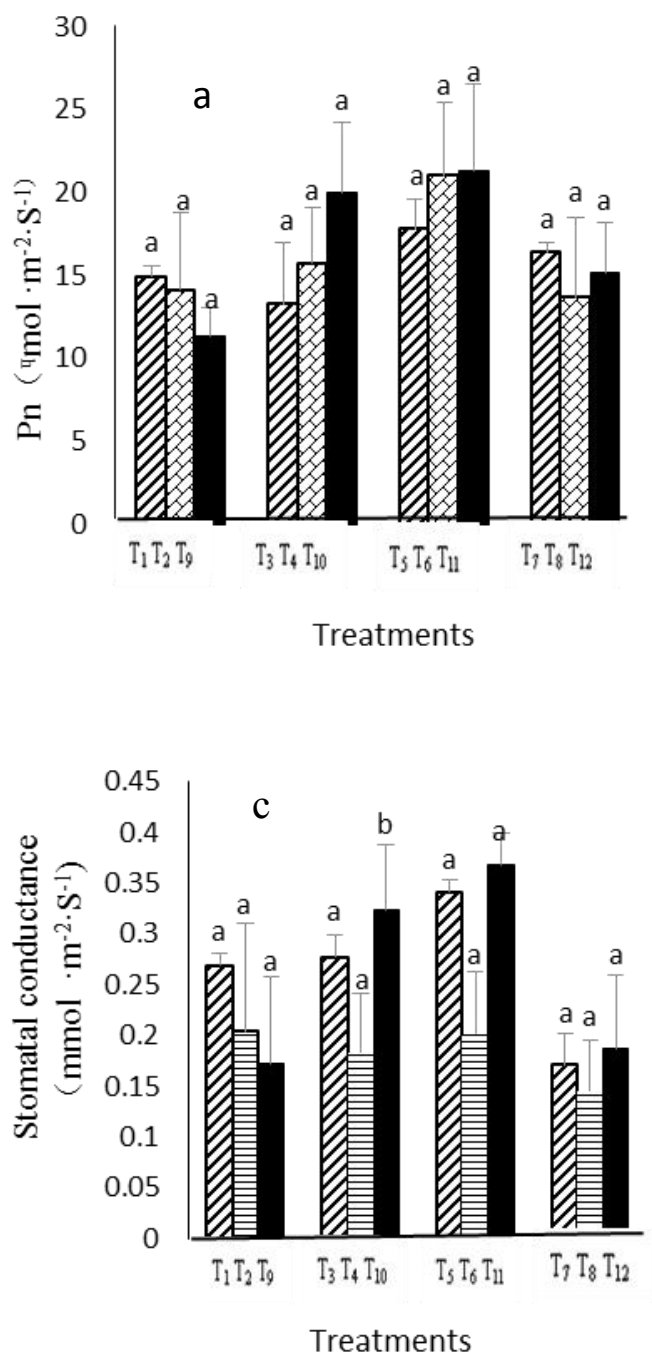
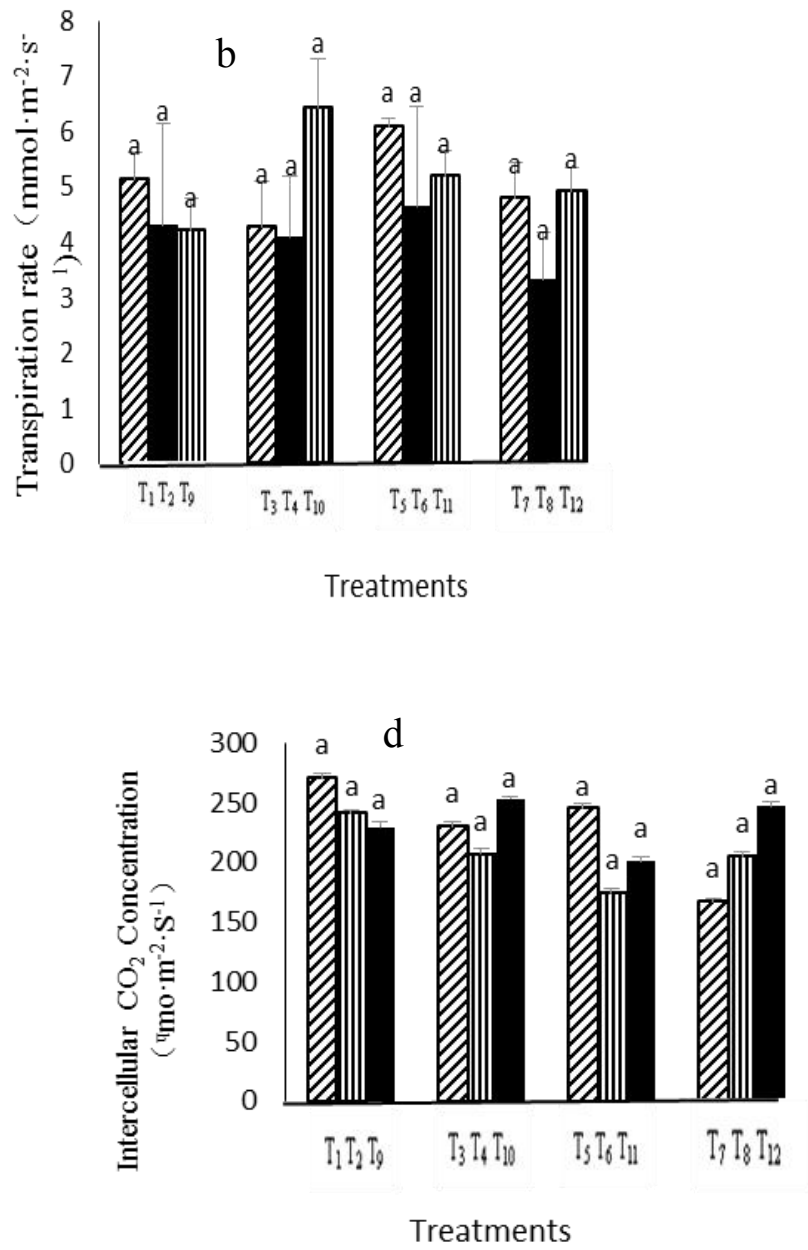

Fig.1 Effects of foliar spraying Se on photosynthetic rate (a), transpiration rate (b), stomatal conductance (c) and intercellular $\mathrm{CO}_{2}$ concentration (d) of pakchoi under different fertilizations

The effects of foliar spraying Se on photosynthetic rate, transpiration rate, stomatal conductance and intercellular $\mathrm{CO}_{2}$ concentration of pakchoi under different fertilization treatments were shown in Fig.1 (a), (b), (c) and (d). The net photosynthetic rate of pakchoi leaf varied significantly with different fertilization treatments, which was significantly higher in organic fertilizer and compound fertilizer treatments than that of the other two treatments. However, there was no significant difference among the application of selenium fertilizer in the same fertilization treatment. The transpiration rate under the Se fertilizer treatments was relatively high, and there was no significant difference between different fertilization treatments and between the foliar Se spraying times. There was no significant difference in stomatal conductance between different fertilization treatments, while, in the same fertilization treatment, there was a significant difference between the foliar Se spraying times, and the stomatal conductance in the treatment of two times Se spraying was higher than that of the control group. The intercellular $\mathrm{CO}_{2}$ concentration increased with Se spraying times under the application of chemical fertilizer. 
The effects of foliar Se spraying on chlorophyll content of pakchoi under different fertilization treatments

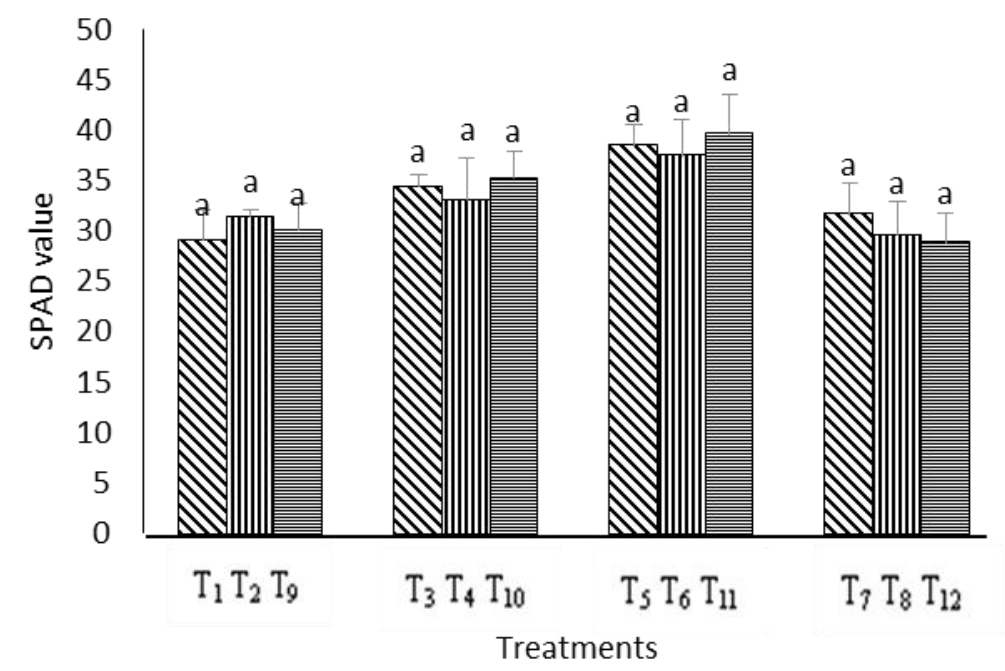

Fig.2 Effects of foliar spraying Se on chlorophyll content (SPAD value) of pakchoi under different fertilization treatments

The effects of foliar spraying Se on chlorophyll content (SPAD value) of pakchoi under different fertilization treatments were shown in Fig.2. Except that at the chemical fertilizer treatments, the foliar spraying Se can effectively increase the chlorophyll content of pakchoi under the other fertilizer treatments. The chlorophyll content under the compound fertilizer treatments was significantly higher than those at the other treatments, and two times Se spraying was bigger than that no selenium and one time spraying.

The effects of foliar spraying Se on the activity of POD, SOD and CAT in pakchoi leaf under different fertilization treatments

The effects of foliar spraying Se on the activity of POD, SOD and CAT in pakchoi leaf under different fertilization treatments were shown in Fig.3 (a), (b) and (c). The POD activity of pakchoi leaves increased with the increase of foliar Se spraying times under the conventional fertilization treatment. Under the treatment with compound fertilizer, the POD activity was also enhanced by the foliar spraying Se. There was a significant difference between different Se spraying times in the same treatment, indicating that the leaf spraying Se had a great influence on the activity of POD. The SOD activity of pakchoi leaves with two times foliar Se spraying was higher than that of the control and one time Se spraying under the conventional fertilization and the organic fertilizer treatments. There was no significant difference in CAT activity between different fertilization treatments, while, there was a significant difference between the spraying times of foliar Se under the same fertilization treatment. 

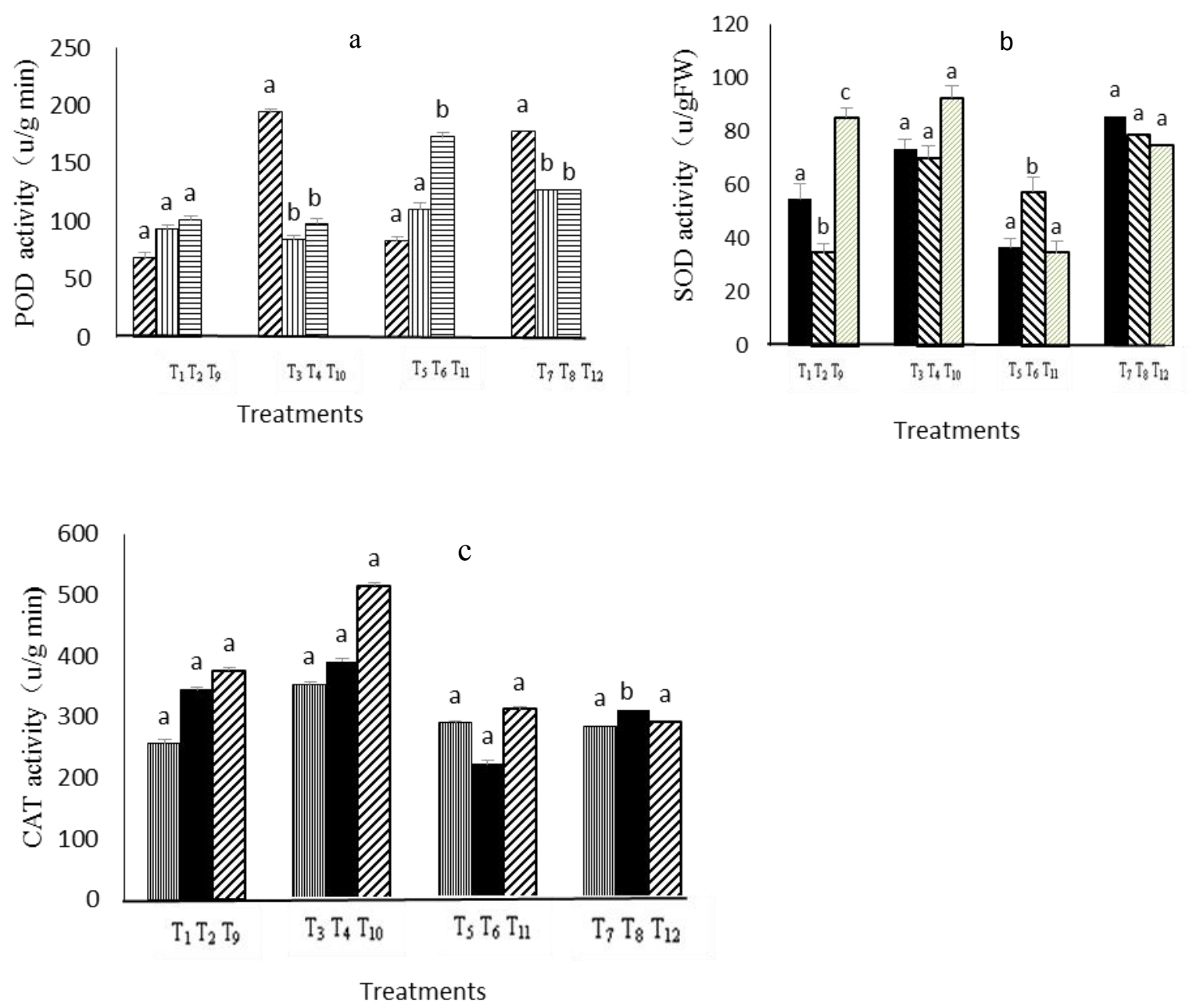

Fig.3 The effects of foliar spraying Se on the activity of POD (a), SOD (b) and CAT(c) in pakchoi leaf under different fertilization treatments

\section{Conclusions}

In the experiment conditions, two times foliar Se spraying increased the net photosynthetic rate, transpiration rate and intercellular $\mathrm{CO}_{2}$ concentration, probably because of Se promoting the formation of ALA, the main raw material of chlorophyll synthesis. Except under the chemical fertilizer treatments, foliar spraying Se improved the content of chlorophyll. The chlorophyll content was relatively high under the treatments of compound fertilizer, which was higher in two times foliar Se spraying than that one time spraying Se. Under the application of organic fertilizer, the SOD and CAT activity can be improved by spraying selenium fertilizer twice, while, the POD activity was increased by foliar spraying Se under the application of compound fertilizer

\section{Acknowledgements}

This work was financially supported by the Research Fund of the Geological Business Center of Tianjin Land and Resources Bureau, Science and Technology Innovation Program of National College Students(201710061101). 


\section{Reference}

[1] H.F. Jia, J.Y. Song, H.H. Wang: Journal of Henan Agricultural University Vol. 40 (2006 ), p. 449.

[2] Y. Wang. Effect of Selenium and Sulfur on the Physiological Characteristic and Quality of Garlic[D].Shandong Agricultural university,2014.

[3] Y.H.Yang. Studies of Selenium Enriched Fertilizer and Fertilizer Efficiency[D].Central South University of Forestry \&Technology,2015.

[4] C. Liang. Effect of Sulfur and Selenium Treatment on Plant Growth and Some Physiological Characteristics of Rice under Cadmium Stress [D].South China University of Technology, 2012. [5] J.Y. Song, J.G. Li, Y.H. Wang: Journal of Henan Agricultural University, Vol. 39 (2005), p. 139.

[6] K.X. Guo, C.X Yao, S.B. Zhou: Journal of Soil and Water Conservation Vol. 24(2010), p. 195. 